\title{
CONSTITUINTES QUÍMICOS DE Parmotrema lichexanthonicum Eliasaro \& Adler - ISOLAMENTO, MODIFICAÇÕES ESTRUTURAIS E AVALIAÇÃO DAS ATIVIDADES ANTIBIÓTICA E CITOTÓXICA
}

\author{
Ana C. Micheletti, Adilson Beatriz, Dênis Pires de Lima e Neli K. Honda* \\ Departamento de Química, Universidade Federal de Mato Grosso do Sul, CP 549, 79070-900 Campo Grande - MS, Brasil \\ Cláudia do Ó Pessoa, Manoel Odorico de Moraes, Letícia Veras Lotufo e Hemerson Iury Ferreira Magalhães \\ Departamento de Fisiologia e Farmacologia, Escola de Medicina, Universidade Federal do Ceará, Rua Coronel Nunes de Melo, \\ 1127, 60431-970 Fortaleza - CE, Brasil \\ Nádia C. P. Carvalho \\ Laboratório de Microbiologia do Hospital Universitário, Universidade Federal de Mato Grosso do Sul, Campo Grande - MS, \\ Brasil
}

Recebido em 30/7/07; aceito em 10/7/08; publicado na web em 2/12/08

\begin{abstract}
CHEMICAL CONSTITUENTS OF Parmotrema lichexanthonicum Eliasaro \& Adler - ISOLATION, STRUCTURE MODIFICATION AND EVALUATION OF ANTIBIOTIC AND CYTOTOXIC ACTIVITIES. From the lichen Parmotrema lichexantonicum were isolated the depsidone salazinic acid, the xanthone lichexanthone, and the depside atranorin. The two major compounds, salazinic acid and lichexanthone, were selected for structure modifications. Salazinic acid afforded $O$-alkyl salazinic acids, some of them potentially cytotoxic against tumor cell lines (HCT-8, SF-295 and MDA/ MB - 435). From lichexanthone were obtained norlichexanthone, 3-O-methylnorlichexanthone, 3-O-methyl-6- $O$-prenylnorlichexanthone, 3,6-di- $O$-prenyl-norlichexanthone, 3,6-bis[(3,3-dimethyloxyran2-il)methoxy]-1-hydroxy-8-methyl-9H-xanten-9-one and 3,6-bis[3-(dimethylamine)propoxy]-1-hydroxy-8-methyl-9H-xanten-9-one. The last compound was the most active against $S$. aureus.
\end{abstract}

Keywords: lichexanthone; salazinic acid; lichens.

\section{INTRODUÇÃO}

Os liquens, associações simbióticas entre fungos e algas verdes ou cianofíceas, apresentam um metabolismo secundário muito característico, sendo que a maioria dos compostos produzidos é considerada exclusiva de liquens. Entre as classes de metabólitos produzidos estão os depsídeos, as depsidonas, os dibenzofuranos, os ácidos úsnicos, as antraquinonas, as xantonas e outras de menor ocorrência. ${ }^{1}$

Em geral, a biossíntese dos compostos fenólicos de liquens ocorre pela rota do acetato-polimalonato. Xantonas e depsidonas naturais são produzidas também por plantas superiores e fungos. No caso de plantas superiores, a rota biossintética para produção de xantonas é mista, sendo uma parte da estrutura produzida a partir da via do chiquimato, e outra a partir da via policetídica. ${ }^{2}$ Uma possibilidade interessante é que xantonas sejam precursoras de depsidonas em plantas, através de reações de hidroperoxilação, por rearranjos de Baeyer-Villiger. ${ }^{3}$ Em fungos e liquens, substâncias das duas classes são biossintetizadas totalmente pela via policetídica. ${ }^{3,4}$

As substâncias produzidas pelos liquens se distinguem entre os produtos naturais, devido às atividades biológicas que apresentam. Além da atividade antibiótica, especialmente sobre bactérias Grampositivas, muitas das substâncias são ativas sobre fungos dermatófitos patógenos. ${ }^{5,6}$ Algumas substâncias têm mostrado ação inibitória da atividade de enzimas virais, tais como HIV-1 integrase e HSV-1 ${ }^{7,8}$ e de outras enzimas como a lipooxigenase, a histidina descarboxilase e a tirosinase, ${ }^{9-12}$ outras inibem a biossíntese de Leucotrieno $\mathrm{B}_{4}\left(\mathrm{LTB}_{4}\right) \cdot{ }^{13-15}$ Além disso muitas substâncias isoladas de liquens têm apresentado também atividade antitumoral. ${ }^{16-18}$

Apesar do potencial de atividades apresentadas pelas substâncias

\footnotetext{
*e-mail: nkhonda@nin.ufms.br
}

de natureza fenólica produzida pelos liquens, essas não são usadas correntemente como medicamentos ou substratos para a preparação desses. A limitação para o uso das substâncias produzidas pelos liquens como protótipo para novas drogas deve-se não somente à baixa solubilidade apresentada, como também, pelo efeito tóxico da maioria dos derivados fenólicos. Entretanto, um dado produto mediante modificações estruturais e/ou funcionalizações pode ter sua solubilidade alterada, a atividade e a toxicidade potencializada, ou não. Assim, através de um planejamento racional é possível modificar uma dada substância alterando a solubilidade e a atividade.

O ácido úsnico, uma das substâncias mais conhecidas entre aquelas produzidas pelos liquens, apresenta, entre outras, a atividade contra microrganismos do gênero Mycobacterium. Na década de 50, Shibata e Miura ${ }^{19}$ prepararam vários derivados com modificações ou derivatizações de grupos funcionais, visando potencializar a atividade e realizar o estudo de correlação estrutura-atividade.

O ácido úsnico apresenta também atividade de inibição do crescimento de células leucêmicas L1210, assim como o ácido polipórico. Visando potencializar a atividade antitumoral desses ácidos sobre células leucêmicas e estabelecer correlações de estrutura e atividade, Cain ${ }^{20}$ e Takai e colaboradores ${ }^{21}$ prepararam vários derivados desses ácidos e embora muitos tenham apresentado atividade, nenhum deles superou a atividade dos ácidos úsnico e polipórico não-modificados.

Kumar e Muller ${ }^{13,15}$ prepararam uma série de análogos dos ácidos barbático, difractáico e obtusático, os quais foram avaliados como inibidores da biossíntese de $\mathrm{LTB}_{4}$ e como agentes antiproliferativos. Muitos dos análogos sintetizados foram potencialmente ativos como inibidores da biossíntese de $\mathrm{LTB}_{4}$.

Xantonas têm mostrado importantes atividades biológicas, destacando-se a modulação de enzimas que são importantes alvos terapêuticos, tais como proteína cinase $\mathrm{C},{ }^{22}$ topoisomerase II, ${ }^{23,24}$ 
acetilcolinesterase, ${ }^{25}$ ciclooxigenases ${ }^{26,27}$ e monoaminoxidases ${ }^{28}$ atividades anti-retroviral, ${ }^{29,30}$ antimalárica, ${ }^{31,32}$ anti-hipertensiva, ${ }^{33}$ anti-inflamatória, citotóxica, ${ }^{24,34}$ e antitumoral. ${ }^{35,36}$ Por isso, o esqueleto xantônico tem sido utilizado como núcleo básico para a síntese de inúmeras moléculas com potencial bioativo. Muitas depsidonas, isoladas de liquens e plantas superiores, ${ }^{3}$ também apresentam grande potencial farmacológico, possuindo atividades importantes, entre as quais inibições de atividade enzimática, ${ }^{37}$ atividades antimicobacteriana, anti-inflamatória, analgésica, antitumoral, citotóxica e antiviral. ${ }^{8,38-41}$

Devido à relevância do potencial farmacológico dessas duas classes de substâncias, o presente trabalho relata as reações de modificações estruturais e funcionalizações da depsidona ácido salazínico (1) e da xantona liquexantona (2), componentes majoritários do líquen Parmotrema lichexanthonicum Eliasaro \& Adler, com o objetivo de avaliar as substâncias obtidas frente às atividades citotóxica e antibiótica.

\section{PARTE EXPERIMENTAL}

\section{Instrumentação e material cromatográfico}

Sílica-gel (Merck 230 - 400 mesh) foi utilizada para cromatografia em coluna. Os espectros de RMN foram obtidos em espectrômetro Bruker DPX-300. As amostras foram solubilizadas em $\mathrm{CDCl}_{3}$, DMSO-d $\mathrm{d}_{6}$ ou acetona-d $\mathrm{d}_{6}$. Os pontos de fusão foram determinados em aparelho Uniscience do Brasil, modelo 498. As análises de ESI-MS foram realizadas em modo positivo, utilizando um equipamento QTOF (Micromass, Manchester, UK), constituído por um duplo quadrupolo $(\mathrm{Qq})$ e um espectrômetro de massas do tipo TOF (analisador de massas por tempo de vôo) de alta resolução. As amostras foram diluídas em solução de $\mathrm{MeOH}: \mathrm{H}_{2} \mathrm{O}$ (1:1), a 1\% de ácido fórmico e as soluções injetadas na interface de electrospray com uma vazão de $10 \mu \mathrm{L} \mathrm{min}{ }^{-1}$ com uma bomba automática (Harvard Apparatus). A voltagem do capilar utilizada foi de $3,0 \mathrm{kV}$ e voltagem do cone de $40 \mathrm{~V}$.

\section{Extração e isolamento dos compostos}

O líquen Parmotrema lichexanthonicum Eliasaro \& Adler foi adquirido em loja de produtos para decoração, em Campo Grande/ MS e foi identificado pelo Dr. M. P. Marcelli e pelo doutorando A. Spielmann, do Instituto de Botânica de São Paulo. A exsicata está depositada no IBT, sob número SP 381512 .

O líquen $(35,00 \mathrm{~g})$ foi triturado e exaustivamente extraído com $\mathrm{CHCl}_{3}$. Os extratos foram reunidos e o solvente evaporado a pressão reduzida $\mathrm{O}$ pó do líquen, sequiencialmente, foi extraído com acetona (3 vezes) e o solvente foi evaporado a pressão reduzida.

Ao extrato clorofórmico seco $(3,63 \mathrm{~g})$, foram adicionadas pequenas porções de $\mathrm{CHCl}_{3}$ gelado e, por centrifugação, foram isolados o depsídeo atranorina (3) (Figura 1) (35,0 mg), que estava presente na maior parte do sobrenadante, e a xantona liquexantona (2) (Figura 1) (1,95 g) na fração sólida. Foram obtidos dados espectrais de ${ }^{1} \mathrm{H}$ e ${ }^{13} \mathrm{C}$ que confirmaram as estruturas dos compostos. $\mathrm{O}$ extrato acetônico seco $(3,85 \mathrm{~g})$ foi tratado com pequenas quantidades de acetona gelada para remoção de pigmentos. O sobrenadante foi retirado após centrifugação e o resíduo foi identificado, após avaliação dos espectros de $\mathrm{RMN}$ de ${ }^{1} \mathrm{H}$ e ${ }^{13} \mathrm{C}$, como a depsidona ácido salazínico (1) (Figura 1) (1,87 g).

Ácido salazínico (1). Sólido branco, p.f. $200{ }^{\circ} \mathrm{C}$ (decompõe). RMN de ${ }^{1} \mathrm{H}\left(300 \mathrm{MHz}, \mathrm{DMSO}-\mathrm{d}_{6}\right) \delta_{\mathrm{H}}$ (H; mult.; int.): 6,87 (H-5; s; 1H), 2,44 (H-8; s; 3H), 10,44 (H-9; s; 1H), 6,82 (H-8'; s; 1H), 4,64<smiles>Cc1cc(O)c(C=O)c2c1C(=O)Oc1c(CO)c(O)c3c(c1O2)C(O)OC3=O</smiles>

(1)

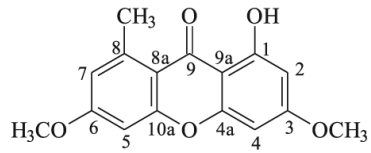

(2)

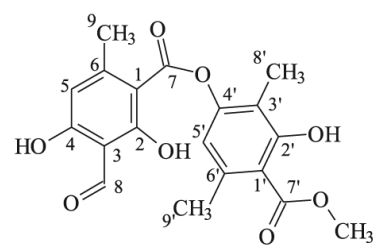

(3)

Figura 1. Estruturas do ácido salazínico (1), da liquexantona (2) e da atranorina (3), isolados do líquen Parmotrema lichexanthonicum

(H-9'; s; 2H), 8,28 (OH; s; 1H), $12,04(\mathrm{OH} ; \mathrm{s} ; 1 \mathrm{H}) .{ }^{13} \mathrm{C}(75 \mathrm{MHz}$, DMSO-d ) $\delta_{\mathrm{C}}: 111,9(\mathrm{C}-1), 163,6$ (C-2), 110,6 (C-3), 164,0 (C-4), 117,4 (C-5), 152,2 (C-6), 160,4 (C-7), 21,4 (C-8), 192,7 (C-9), 109,7 (C-1'), 152,8 (C-2'), 123,4 (C-3'), 148,1 (C-4'), 138,0 (C-5'), 137,3 (C-6'), 165,9 (C-7'), 94,8 (C-8'), 52,7 (C-9'). ${ }^{42}$ Rendimento 5,3\%.

Liquexantona (2). Sólido amarelo, p.f. $188-190{ }^{\circ} \mathrm{C}$. RMN de ${ }^{1} \mathrm{H}$ $\left(300 \mathrm{MHz}, \mathrm{CDCl}_{3}\right) \delta_{\mathrm{H}}(\mathrm{H} ;$ mult.; $J$ em Hz; int.): 6,26 (H-2; $d ; 2,6 ; 1 \mathrm{H})$, $6,28$ (H-4; $d ; 2,6 ; 1 \mathrm{H}), 6,63(\mathrm{H}-5 ; d ; 2,6 ; 1 \mathrm{H}), 6,62(\mathrm{H}-7 ; s l ; 1 \mathrm{H}), 2,81$ (Me-8; $s ; 3 \mathrm{H}), 13,36(\mathrm{OH} ; s ; 1 \mathrm{H}), 3,85(\mathrm{OMe} ; s ; 3 \mathrm{H}), 3,87(\mathrm{OMe} ; s$; $3 \mathrm{H}) .{ }^{13} \mathrm{C}\left(75 \mathrm{MHz}, \mathrm{CDCl}_{3}\right) \delta_{\mathrm{C}}: 163,7$ (C-1), 96,7 (C-2), 165,7 (C-3), 92,0 (C-4), 98,4 (C-5), 163,7 (C-6), 115,4 (C-7), 143,4 (C-8), 182,3 (C-9), 156,9 (C-4a), 112,8 (C-8a), 104,1 (C-9a), 159,3 (C-10a), 23,4 (Me-C8). ${ }^{42}$ Rendimento $5,6 \%$.

Atranorina (3). Sólido branco, p.f. $196^{\circ} \mathrm{C}$ (decompõe). RMN de ${ }^{1} \mathrm{H}\left(300 \mathrm{MHz}, \mathrm{CDCl}_{3}\right) \delta_{\mathrm{H}}(\mathrm{H} ;$ mult.; int.): 6,39 (H-5; $s ; 1 \mathrm{H}), 10,35$ $(\mathrm{H}-8 ; s ; 1 \mathrm{H}), 2,68$ (H-9; $s ; 3 \mathrm{H}), 6,50(\mathrm{H}-5$ '; $s ; 1 \mathrm{H}), 2,08$ (H-8'; $s$; $3 \mathrm{H}), 2,54$ (H-9'; $s ; 3 \mathrm{H}), 3,98(\mathrm{OMe} ; s ; 3 \mathrm{H}), 11,93(\mathrm{OH} ; s ; 1 \mathrm{H}), 12,49$ $(\mathrm{OH} ; s ; 1 \mathrm{H}), 12,54(\mathrm{OH} ; s ; 1 \mathrm{H}) .{ }^{13} \mathrm{C}\left(75 \mathrm{MHz}, \mathrm{CDCl}_{3}\right) \delta_{\mathrm{C}}: 102,9(\mathrm{C}-$ 1), 169,1 (C-2), 108,6 (C-3), 167,5 (C-4), 112,9 (C-5), 152,4 (C-6), 169,7 (C-7), 193,8 (C-8), 25,6 (C-9), 116,8 (C-1'), 162,9 (C-2'), 110,3 (C-3'), 151,9 (C-4'), 116,0 (C-5'), 139,9 (C-6'), 172,2 (C-7'), 24,0 (C-8'), 9,4 (C-9'), 52,3 (OMe-C7'). ${ }^{43}$ Rendimento $0,1 \%$.

\section{Reações de modificação estrutural}

Derivados do ácido salazínico (4) - (9)

Uma mistura de ácido salazínico (1) (150,0 mg, 0,4 mmol) e um álcool ( $n$-propanol, $n$-butanol, $n$-pentanol, $n$-hexanol, iso-propanol, terc-butanol $-25,0 \mathrm{~mL}$ ) foi aquecida a uma temperatura de $90{ }^{\circ} \mathrm{C}$, exceto com iso-propanol e terc-butanol que foram aquecidos sob refluxo. As reações foram monitoradas por $\mathrm{CCD}$ e os tempos variaram de 23 a 150 h. As misturas reacionais, após evaporação do solvente, foram fracionadas por cromatografia em coluna de sílica, eluídas com um gradiente de hexano/ acetato de etila, resultando nos produtos (4) a (9) (Figura 2).

\section{Ácido 8', 9'-di-O-n-propil salazínico (4)}

Sólido branco, p.f. $150-152{ }^{\circ} \mathrm{C}$. EM, $m / z: 473,1393$ [M+]. RMN de ${ }^{1} \mathrm{H}\left(300 \mathrm{MHz}, \mathrm{CDCl}_{3}\right) \delta_{\mathrm{H}}(\mathrm{H} ;$ mult.; $J$ em Hz; int.): 6,72 (H-5; $s$; $1 \mathrm{H}), 2,50(\mathrm{H}-8 ; s ; 3 \mathrm{H}), 6,46(\mathrm{H}-8$ '; $s ; 1 \mathrm{H}), 10,44(\mathrm{H}-9 ; s ; 1 \mathrm{H}), 4,76$ (H-9'; $2 d ; 11,6 ; 2 \mathrm{H}), 3,70$ (H-10; $t ; 6,8 ; 2 \mathrm{H}), 3,50(\mathrm{H}-10$ '; $t ; 6,6 ; 2 \mathrm{H})$, 


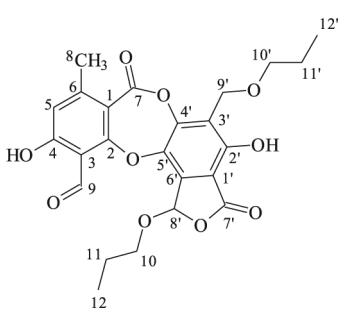

(4)

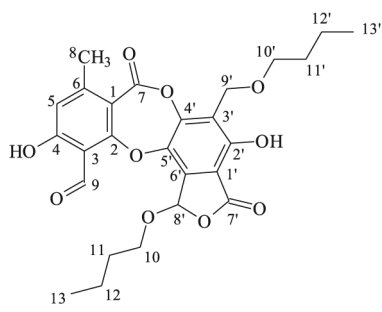

(6)

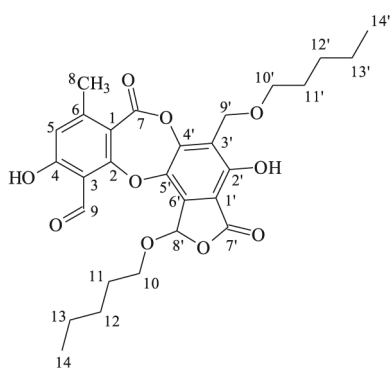

(8)

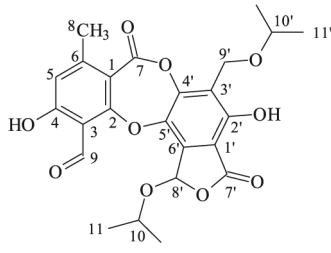

(5)

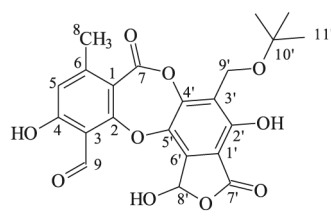

(7)

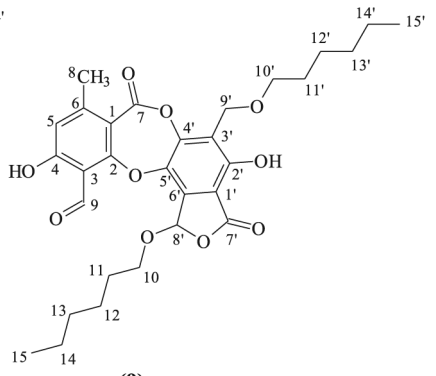

(9)
Figura 2. Ácidos O-alquil salazínicos (4) a (9), obtidos a partir de reações do ácido salazínico com álcoois

1,58 (H-11, 11'; $m$; 4H), 0,89 (H-12, 12'; 2t; 7,5; 6H), 8,60 (OH; $s$; $1 \mathrm{H}), 12,10(\mathrm{OH} ; s ; 1 \mathrm{H}) \cdot{ }^{13} \mathrm{C}\left(75 \mathrm{MHz}, \mathrm{CDCl}_{3}\right) \delta_{\mathrm{C}}: 111,7(\mathrm{C}-1), 164,2$ (C-2), 110,3 (C-3), 165,6 (C-4), 118,2 (C-5), 153,6 (C-6), 159,7 (C-7), 22,3 (C-8), 192,9 (C-9), 71,5 (C-10), 109,2 (C-1'), 153,9 (C-2'), 120,2 (C-3'), 149,3 (C-4'), 138,4 (C-5'), 134,9 (C-6'), 167,6 (C-7'), 100,1 (C-8'), 62,3 (C-9'), 73,4 (C-10'), 22,5, 22,8 (C-11, 11'), 10,1, 10,5 (C-12, 12'). Rendimento $35 \%$.

Ácido 8', 9'-di-O-isopropil salazínico (5)

Sólido branco, p.f. 202-204 ${ }^{\circ} \mathrm{C}$. EM, $m / z: 473,1093$ [M+]. RMN de ${ }^{1} \mathrm{H}\left(300 \mathrm{MHz}, \mathrm{CDCl}_{3}\right) \delta_{\mathrm{H}}(\mathrm{H} ;$ mult; $J$ em Hz; int.): 6,73 (H-5; s; $1 \mathrm{H}), 2,51(\mathrm{H}-8 ; s ; 3 \mathrm{H}), 6,43(\mathrm{H}-8$ '; $s ; 1 \mathrm{H}), 10,44(\mathrm{H}-9 ; s ; 1 \mathrm{H}), 5,00$ (H-9'; $s ; 2 \mathrm{H}), 4,23$ (H-10; $t ; 6,8 ; 2 \mathrm{H}), 3,77$ (H-10'; $m ; 2 \mathrm{H}), 1,22,1,25$ $(\mathrm{H}-11,11$ '; $2 d ; 6,0 ; 12 \mathrm{H}), 8,73(\mathrm{OH} ; s ; 1 \mathrm{H}), 12,10(\mathrm{OH} ; s ; 1 \mathrm{H}) .{ }^{13} \mathrm{C}$ $\left(75 \mathrm{MHz}, \mathrm{CDCl}_{3}\right) \delta_{\mathrm{C}}: 111,8$ (C-1), 164,4 (C-2), 110,4 (C-3), 165,6 (C-4), 118,1 (C-5), 153,6 (C-6), 159,8 (C-7), 22,3 (C-8), 193,1 (C-9), 72,8 (C-10), 109,3 (C-1'), 154,1 (C-2'), 120,5 (C-3'), 149,2 (C-4'), 138,6 (C-5'), 135,2 (C-6'), 167,7 (C-7'), 98,3 (C-8'), 60,3 (C-9'), 72,9 (C-10'), 20,9-22,9 (C-11, 11'). Rendimento 6\%.

\section{Ácido 8', 9'-di-O-n-butil salazínico (6)}

Sólido branco, p.f. $120-122{ }^{\circ} \mathrm{C}$. EM, $m / z: 501,1949\left[\mathrm{M}^{+}\right]$. RMN de ${ }^{1} \mathrm{H}\left(300 \mathrm{MHz}, \mathrm{CDCl}_{3}\right) \delta_{\mathrm{H}}(\mathrm{H} ;$ mult; $J$ em Hz; int.): 6,72 (H-5; $s$; 1H), 2,49 (H-8; $s ; 3 \mathrm{H}), 6,46(\mathrm{H}-8 ; ; s ; 1 \mathrm{H}), 10,45(\mathrm{H}-9 ; s ; 1 \mathrm{H}), 4,76$ (H-9'; $2 d ; 11,8 ; 2 \mathrm{H}), 3,70$ (H-10; $t ; 6,6 ; 2 \mathrm{H}), 3,60$ (H-10'; $t ; 6,5$; 2H), 1,56 (H-11, 11'; $m ; 4 \mathrm{H}), 1,34$ (H-12, 12'; $m ; 4 \mathrm{H}), 0,88$ (H-13, 13 '; $2 t ; 6,5 ; 6 \mathrm{H}), 8,60(\mathrm{OH} ; s ; 1 \mathrm{H}), 12,10(\mathrm{OH} ; s ; 1 \mathrm{H}) .{ }^{13} \mathrm{C}(75 \mathrm{MHz}$, $\left.\mathrm{CDCl}_{3}\right) \delta_{\mathrm{C}}: 111,7(\mathrm{C}-1), 164,2$ (C-2), 110,3 (C-3), 165,6 (C-4), 118,2
(C-5), 153,6 (C-6), 159,7 (C-7), 22,3 (C-8), 192,9 (C-9), 69,7 (C10), 109,2 (C-1'), 153,9 (C-2'), 120,1 (C-3'), 149,2 (C-4'), 138,4 (C-5'), 134,9 (C-6'), 167,6 (C-7'), 100,1 (C-8'), 62,7 (C-9'), 71,5 (C-10'), 31,2, 31,6 (C-11, 11'), 19,2 (C-12, 12'), 13,8 (C-13, 13'). Rendimento $28 \%$.

\section{Ácido 9'-O-terc-butil salazínico (7)}

Sólido branco, p.f. $150{ }^{\circ} \mathrm{C}$ (decompõe). EM, $m / z: 445,1264\left[\mathrm{M}^{+}\right]$. RMN de ${ }^{1} \mathrm{H}\left(300 \mathrm{MHz}, \mathrm{CDCl}_{3}\right) \delta_{\mathrm{H}}(\mathrm{H} ;$ mult ; int.): 6,63 (H-5, H-8'; s; 2H), 2,51 (H-8; $s ; 3 \mathrm{H}), 10,50(\mathrm{H}-9 ; s ; 1 \mathrm{H}), 4,79$ (H-9'; $s ; 2 \mathrm{H}), 1,36$ $(\mathrm{H}-11$ '; $s ; 9 \mathrm{H}), 5,58(\mathrm{OH} ; s ; 1 \mathrm{H}), 9,10(\mathrm{OH} ; s ; 1 \mathrm{H}), 12,10(\mathrm{OH} ; s$; $1 \mathrm{H}) .{ }^{13} \mathrm{C}\left(75 \mathrm{MHz}, \mathrm{CDCl}_{3}\right) \delta_{\mathrm{C}}: 111,9(\mathrm{C}-1), 164,0(\mathrm{C}-2), 110,2(\mathrm{C}-3)$, 165,6 (C-4), 118,0 (C-5), 153,6 (C-6), 159,8 (C-7), 22,3 (C-8), 193, 2 (C-9), 109,1 (C-1'), 153,9 (C-2'), 119,8 (C-3'), 148,8 (C-4'), 138,1 (C-5'), 136,3 (C-6'), 167,2 (C-7'), 95,4 (C-8'), 56,0 (C-9'), 76,2 (C-10'), 27,3 (C-11'). ${ }^{44}$ Rendimento $16 \%$.

\section{Ácido 8', 9'-di-O-n-pentil salazínico $(\mathbf{8})$}

Sólido branco, p.f. $96-98{ }^{\circ} \mathrm{C}$. EM, $m / z: 529,1944\left[\mathrm{M}^{+}\right]$. RMN de ${ }^{1} \mathrm{H}\left(300 \mathrm{MHz}, \mathrm{CDCl}_{3}\right) \delta_{\mathrm{H}}(\mathrm{H} ;$ mult.; $J$ em Hz; int.): 6,77 (H-5; $s ; 1 \mathrm{H}), 2,44(\mathrm{H}-8 ; s ; 3 \mathrm{H}), 6,46(\mathrm{H}-8$; $s ; 1 \mathrm{H}), 10,45(\mathrm{H}-9 ; s ; 1 \mathrm{H})$, $4,74$ (H-9'; $2 d ; 11,7 ; 2 \mathrm{H}), 3,75$ (H-10; $t ; 6,4 ; 2 \mathrm{H}), 3,58$ (H-10'; $t$; $6,6 ; 2 \mathrm{H}), 1,58$ (H-11, 11'; $m ; 4 \mathrm{H}), 1,28$ (H-12, 12'-13, 13'; $m$; 8H), $0,85(\mathrm{H}-14,14 ; m ; 6 \mathrm{H}), 8,61(\mathrm{OH} ; s ; 1 \mathrm{H}), 12,21(\mathrm{OH} ; s ; 1 \mathrm{H}) .{ }^{13} \mathrm{C}$ $\left(75 \mathrm{MHz}, \mathrm{CDCl}_{3}\right) \delta_{\mathrm{C}}: 111,7(\mathrm{C}-1), 164,2$ (C-2), 110,3 (C-3), 165,6 (C-4), 118,2 (C-5), 153,6 (C-6), 159,7 (C-7), 22,5 (C-8), 192,9 (C-9), 69,6 (C-10), 109,2 (C-1'), 153,9 (C-2'), 120,1 (C-3'), 149,2 (C-4'), 138,4 (C-5'), 134,9 (C-6'), 167,6 (C-7'), 100,7 (C-8'), 62,2 (C-9'), 71,6 (C-10'), 28,8 e 29,3 (C-11, 11'), 27,8 e 28,1 (C-12, 12'), 14,2 (C-14, 14'). Rendimento $35 \%$.

Ácido 8', 9'-di-O-n-hexil salazínico (9)

Sólido branco, p.f. $92-94{ }^{\circ} \mathrm{C}$. EM, $m / z: 557,2350\left[\mathrm{M}^{+}\right]$. RMN de ${ }^{1} \mathrm{H}\left(300 \mathrm{MHz}, \mathrm{CDCl}_{3}\right) \delta_{\mathrm{H}}(\mathrm{H} ;$ mult; $J$ em Hz; int.): 6,72 (H-5; $s ; 1 \mathrm{H})$, 2,50 (H-8; $s ; 3 \mathrm{H}), 6,46$ (H-8'; $s ; 1 \mathrm{H}), 10,44$ (H-9; $s ; 1 \mathrm{H}), 4,70$ (H-9'; $t ; 11,8 ; 2 \mathrm{H}), 3,76$ (H-10; $t ; 6,3 ; 2 \mathrm{H}), 3,57$ (H-10'; $t ; 6,6 ; 2 \mathrm{H}), 1,50$ (H-11, 11'; m; 4H), 1,24 (H-12, 12'- 14, 14'; sl; 12H), 0,85 (H-15, $\left.15^{\prime} ; m ; 6 \mathrm{H}\right), 12,10(\mathrm{OH} ; s ; 1 \mathrm{H}) .{ }^{13} \mathrm{C}\left(75 \mathrm{MHz}, \mathrm{CDCl}_{3}\right) \delta_{\mathrm{C}}: 111,7(\mathrm{C}-1)$, 164,2 (C-2), 110,3 (C-3), 165,6 (C-4), 118, 2 (C-5), 153,7 (C-6), 159,7 (C-7), 22,5(C-8), 192,9 (C-9), 70,1 (C-10), 109,2 (C-1'), 153,9 (C-2'), 120,2 (C-3'), 149,2 (C-4'), 138,0 (C-5'), 134,9 (C-6'), 167,6 (C-7'), 100,1 (C-8'), 62,8 (C-9'), 71,9 (C-10'), 29,0 (C-11, 11'), 31,4 (C-12, 12'), 22,0 (C-14, 14'), 14,0 (C-15, 15'). Rendimento $40 \%$.

\section{Derivados da liquexantona}

\section{Norliquexantona $(\mathbf{1 0})$}

$53,7 \mathrm{mg}(0,19 \mathrm{mmol})$ de liquexantona (2) foram dissolvidas em 10 $\mathrm{mL}$ de $\mathrm{CH}_{2} \mathrm{Cl}_{2}$ anidro sob agitação em atmosfera de $\mathrm{N}_{2}$ e a solução foi mantida em banho de gelo por $30 \mathrm{~min}$. Foram, então, adicionados 0,4 $\mathrm{mL}$ de $\mathrm{BBr}_{3}(4,17 \mathrm{mmol})$ e a temperatura foi gradativamente elevada, até atingir aproximadamente $30^{\circ} \mathrm{C}$. A reação foi acompanhada por CCD e após $18 \mathrm{~h}$ foi interrompida, adicionando-se água à mistura reacional. O sobrenadante foi removido e o resíduo foi dissolvido em acetona. A solução obtida foi seca com $\mathrm{Na}_{2} \mathrm{SO}_{4}$ e concentrada em evaporador rotativo. A mistura foi purificada por cromatografia em coluna de sílica gel, usando como eluente hexano/ acetato de etila em gradiente de polaridade. Rendimento 70\%. Sólido amarelo, p.f. $275^{\circ} \mathrm{C}$ (decompõe). RMN de ${ }^{1} \mathrm{H}\left(300 \mathrm{MHz}, \mathrm{DMSO}-\mathrm{d}_{6}\right) \delta_{\mathrm{H}}(\mathrm{H} ;$ mult.; $J$ em Hz; int.): 6,11 (H-2; $d ; 2,2 ; 1 \mathrm{H}), 6,26$ (H-4; $d ; 2,2 ; 1 \mathrm{H}), 6,64$ (H-5; sl; 1H), 6,63 (H-7; sl; 1H), 2,71 (Me-8; s; 3H), 10,83 (OH; $s ; 2 \mathrm{H}), 13,4(\mathrm{OH} ; s ; 1 \mathrm{H}) .{ }^{13} \mathrm{C}\left(75 \mathrm{MHz}, \mathrm{DMSO}-\mathrm{d}_{6}\right) \delta_{\mathrm{C}}: 163,0(\mathrm{C}-1)$, 97,8 (C-2), 164,7 (C-3), 93,2 (C-4), 100,5 (C-5), 162,8 (C-6), 116,2 
(C-7), 142,8 (C-8), 181,4 (C-9), 156,4 (C-4a), 110,9 (C-8a), 102,1 (C-9a), 158,8 (C-10a), 23,0 (Me-C8). ${ }^{42}$

\section{3-O-metilnorliquexantona $(\mathbf{1 1})$}

$55,1 \mathrm{mg}(0,19 \mathrm{mmol})$ de liquexantona (2) foram adicionados a $41,8 \mathrm{mg}(0,75 \mathrm{mmol})$ de $\mathrm{KOH}$ e $5 \mathrm{~mL}$ de dietilenoglicol. A mistura foi mantida em refluxo (temperatura de aproximadamente $240^{\circ} \mathrm{C}$ ) por 4 h. Após este período, a solução foi neutralizada com solução $1 \mathrm{M}$ de $\mathrm{HCl}$ e em seguida extraída com acetato de etila. A fase orgânica foi seca com $\mathrm{Na}_{2} \mathrm{SO}_{4}$ e o solvente evaporado em evaporador rotativo (80,4 mg), sendo a mistura submetida à cromatografia em coluna de sílica gel com hexano/ acetato de etila em gradiente. Rendimento: $13,15 \%$. Sólido amarelo, p.f. $253-255^{\circ} \mathrm{C}$. RMN de ${ }^{1} \mathrm{H}(300 \mathrm{MHz}$, acetona-d $\left.{ }_{6}\right) \delta_{\mathrm{H}}(\mathrm{H} ;$ mult.; $J$ em Hz; int.): 6,24 (H-2; $d ; 2,4 ; 1 \mathrm{H}), 6,39$ (H-4; $d ; 2,4 ; 1 \mathrm{H}), 6,70$ (H-5, H-7; sl; 2H), 2,80 (Me-8; $s ; 3 \mathrm{H}), 3,90$ $(\mathrm{OMe} ; s ; 3 \mathrm{H}), 13,40(\mathrm{OH} ; s ; 1 \mathrm{H}) .{ }^{13} \mathrm{C}\left(75 \mathrm{MHz}\right.$, acetona-d $\left.{ }_{6}\right) \delta_{\mathrm{C}}: 164,2$ (C-1), 98,0 (C-2), 167,5 (C-3), 93,0 (C-4), 102,0 (C-5), 164,2 (C-6), 117,5 (C-7), 145,0 (C-8), 183,6 (C-9), 158,4 (C-4a), 113,1 (C-8a), 104,9 (C-9a), 160,8 (C-10a), 23,9 (Me-C8). ${ }^{42}$

\section{3-O-metil-6-O-prenilnorliquexantona (12)}

A uma solução de 3-O-metilnorliquexantona (11) $[5,8 \mathrm{mg}(0,02$ $\mathrm{mmol})]$ em acetona $(5 \mathrm{~mL})$, foram adicionados $50 \mu \mathrm{L}(0,44 \mathrm{mmol})$ de brometo de 3,3-dimetilalila e 5,4 $\mathrm{mg}(0,04 \mathrm{mmol})$ de $\mathrm{K}_{2} \mathrm{CO}_{3}$, sob agitação à temperatura ambiente. $\mathrm{O}$ desenvolvimento da reação foi acompanhado por CCD e, após um período de aproximadamente 60 $\mathrm{h}$, a reação foi interrompida com a adição de água seguida de extração com $\mathrm{CHCl}_{3}$, em funil de separação. A fase orgânica foi seca com $\mathrm{Na}_{2} \mathrm{SO}_{4}$ e o solvente evaporado em evaporador rotativo, obtendo-se um sólido marrom. Pf. 77-79 ${ }^{\circ} \mathrm{C}$. EM, $m / z$ : 341,1403 [M $\left.{ }^{+}\right]$. RMN de ${ }^{1} \mathrm{H}(300 \mathrm{MHz}$, acetona-d $) \delta_{\mathrm{H}}(\mathrm{H} ;$ mult ; $J$ em Hz; int.): 1,77 (H-14; $s l ; 3 \mathrm{H}), 1,81(\mathrm{H}-13 ; s l ; 3 \mathrm{H}), 2,83(\mathrm{Me}-\mathrm{C} 8 ; s ; 3 \mathrm{H}), 3,86(\mathrm{OMe} ; s ; 3 \mathrm{H})$, $4,58(\mathrm{H}-10 ; d ; 6,7 ; 2 \mathrm{H}), 5,49$ (H-11; tl; 6,7; 1H), 6,28 (H-2; $d ; 2,0$; $1 \mathrm{H}), 6,32(\mathrm{H}-4 ; d ; 2,0 ; 1 \mathrm{H}), 6,67(\mathrm{H}-5 ; s l ; 1 \mathrm{H}), 6,66(\mathrm{H}-7 ; s l ; 1 \mathrm{H})$, $13,39(\mathrm{OH} ; s ; 1 \mathrm{H})$.

\section{3,6-di-O-prenilnorliquexantona (13)}

$50,0 \mathrm{mg}(0,19 \mathrm{mmol})$ de norliquexantona (10) e 43,0 $\mathrm{mg}(0,31$ mmol) de $\mathrm{K}_{2} \mathrm{CO}_{3}$ foram dissolvidos em $10 \mathrm{~mL}$ de acetona. À solução foram adicionados $40 \mu \mathrm{L}(0,35 \mathrm{mmol})$ de brometo de 3,3-dimetilalila, mantendo-se sob agitação e temperatura ambiente (aproximadamente $30^{\circ} \mathrm{C}$ ). A reação foi acompanhada por CCD e após $23 \mathrm{~h}$ foi interrompida, evaporando-se o solvente. A mistura reacional foi fracionada por CCDP (cromatografia em camada delgada preparativa) no eluente hexano/acetato de etila 30\%. Rendimento: $55 \%$. Sólido amarelo, p.f. $105-106{ }^{\circ} \mathrm{C}$. EM, $m / z: 395,1992$ [M+]. Os dados referentes aos deslocamentos químicos de $\mathrm{RMN}$ de ${ }^{1} \mathrm{H}$ e ${ }^{13} \mathrm{C}$ estão descritos na Tabela 1.

\section{3,6-bis[3-(dimetilamino)propóxi]-1-hidróxi-8-metil-9H-xanten-9- ona $(\mathbf{1 4})$}

$86,9 \mathrm{mg}(0,55 \mathrm{mmol})$ de cloreto de (3-cloropropil)dimetilamônio foi dissolvido em $4 \mathrm{~mL}$ de uma solução saturada de $\mathrm{NaOH}$ e, posteriormente, extraído com tolueno em funil de separação. Em um balão de fundo redondo, adicionou-se $31,6 \mathrm{mg}(0,57 \mathrm{mmol}) \mathrm{de}$ $\mathrm{KOH}$ a uma solução de $30,8 \mathrm{mg}(0,12 \mathrm{mmol})$ de norliquexantona (10) em etanol absoluto. A solução permaneceu sob agitação durante aproximadamente $30 \mathrm{~min}$, seguida por evaporação do solvente. Ao balão foi adicionada a 3-cloropropildimetilamina dissolvida em 20 $\mathrm{mL}$ de tolueno e $10 \mathrm{~mL}$ de DMSO. A mistura foi refluxada por 48 $\mathrm{h}$ e a reação foi interrompida com a adição de uma solução aquosa saturada de $\mathrm{Na}_{2} \mathrm{CO}_{3}$ A mistura reacional foi extraída com acetato de etila, por várias vezes, e os extratos reunidos. A fase acetato foi
Tabela 1. Deslocamentos químicos de $\mathrm{RMN}$ de ${ }^{1} \mathrm{H}(300 \mathrm{MHz})$ e ${ }^{13} \mathrm{C}$ $(75 \mathrm{MHz})$ para (13) em $\mathrm{CDCl}_{3}$

\begin{tabular}{|c|c|c|}
\hline posição & $\delta_{\mathrm{H}}$ & $\delta_{\mathrm{C}}$ \\
\hline 1 & $13,37, s$ & 163,6 \\
\hline 2 & $6,28 d, J=2,2 \mathrm{~Hz}$ & 97,3 \\
\hline 3 & & 165,1 \\
\hline 4 & $6,31 d, J=2,2 \mathrm{~Hz}$ & 92,7 \\
\hline 5 & $6,65,6,66, s l$ & 99,1 \\
\hline 6 & & 163,0 \\
\hline 7 & $6,65,6,66, s l$ & 115,9 \\
\hline 8 & & 143,3 \\
\hline 9 & & 182,3 \\
\hline $4 a$ & & 156,9 \\
\hline $8 \mathrm{a}$ & & 112,8 \\
\hline $9 \mathrm{a}$ & & 104,0 \\
\hline $10 \mathrm{a}$ & & 159,3 \\
\hline $8-\mathrm{CH}_{3}$ & $2,81, s$ & 23,4 \\
\hline 10 & $4,56,2 d, J=6,4 \mathrm{~Hz}$ & $65,2,65,3$ \\
\hline 11 & $5,47, t l$ & $118,6,118,8$ \\
\hline 12 & - & $139,1,139,3$ \\
\hline 13 & $1,75-1,81, s l$ & 25,8 \\
\hline 14 & & 18,2 \\
\hline
\end{tabular}

$s=$ singleto; $s l=$ singleto largo; $d=$ dubleto; $t l=$ tripleto largo; $J=$ constante de acoplamento

lavada com uma solução de $\mathrm{HCl} 1 \mathrm{M}$ e, a seguir, neutralizada com $\mathrm{Na}_{2} \mathrm{CO}_{3}$ e a mistura novamente extraída com acetato de etila. Após secagem com $\mathrm{Na}_{2} \mathrm{SO}_{4}$ o solvente foi evaporado. Rendimento: $62,5 \%$. Sólido amarelo, p.f. $154-156{ }^{\circ} \mathrm{C}$. EM, $m / z:$ 429,2386 [M+]. Os dados referentes aos deslocamentos químicos de $\mathrm{RMN}$ de ${ }^{1} \mathrm{H}$ e ${ }^{13} \mathrm{C}$ estão descritos na Tabela 2.

\section{3,6-bis[(3,3-dimetiloxiran-2-il)metóxi]-1-hidróxi-8-metil-9H-} xanten-9-ona $(\mathbf{1 5})$

A uma solução de $31,2 \mathrm{mg}(0,085 \mathrm{mmol})$ de 3,6-di- $O$-prenilnorliquexantona (13) em $15 \mathrm{~mL}$ de $\mathrm{CHCl}_{3}$ foram adicionados 47,6 mg $(0,31 \mathrm{mmol})$ de ácido $m$-cloroperbenzóico (MCPBA). A solução permaneceu sob agitação por aproximadamente $170 \mathrm{~h}$, sendo interrompida pela adição de água. Em seguida, adicionou-se uma solução saturada de $\mathrm{Na}_{2} \mathrm{CO}_{3}$ e a mistura reacional foi extraída em funil de separação com $\mathrm{CHCl}_{3}$. A fase orgânica foi seca com $\mathrm{Na}_{2} \mathrm{SO}_{4}$ e o solvente evaporado. $\mathrm{O}$ resíduo foi submetido à separação por cromatografia em coluna de sílica, em gradiente de hexano/ acetato de etila. Rendimento: $17 \%$. Sólido amarelo, p.f. $91-92^{\circ} \mathrm{C}$. Os dados referentes aos deslocamentos químicos de RMN de ${ }^{1} \mathrm{H}$ e ${ }^{13} \mathrm{C}$ estão descritos na Tabela 3 .

\section{Ensaios biológicos}

Atividade citotóxica

As linhagens de células MDA/MB-435 (mama-humano), HCT-8 (cólon-humano) e SF-295 (glioblastoma-humano), cedidas pelo Instituto Nacional do Câncer (EUA), foram cultivadas em meio RPMI 1640 (meio nutritivo adquirido da ATCC), suplementado com 10\% de soro fetal bovino e $1 \%$ de antibióticos, mantidas em estufa à 37 
Tabela 2. Deslocamentos químicos de $\mathrm{RMN}$ de ${ }^{1} \mathrm{H}(300 \mathrm{MHz})$ e ${ }^{13} \mathrm{C}$ (75 MHz) para o composto (14) em acetona-d ${ }_{6}$

\begin{tabular}{|c|c|c|}
\hline posição & $\delta_{\mathrm{H}}$ & $\delta_{\mathrm{C}}$ \\
\hline 1 & $13,35, s$ & 164,6 \\
\hline 2 & $6,26, d, J=2,2 \mathrm{~Hz}$ & 97,9 \\
\hline 3 & & 166,5 \\
\hline 4 & $6,39, d, J=2,2 \mathrm{~Hz}$ & 93,1 \\
\hline 5 & $6,80, s l$ & 99,9 \\
\hline 6 & & 164,6 \\
\hline 7 & $6,76, s l$ & 116,7 \\
\hline 8 & & 143,9 \\
\hline 9 & & 183,0 \\
\hline $4 a$ & & 157,9 \\
\hline $8 \mathrm{a}$ & & 113,6 \\
\hline $9 \mathrm{a}$ & & 104,4 \\
\hline $10 \mathrm{a}$ & & 157,9 \\
\hline $8-\mathrm{CH}_{3}$ & $2,80, \mathrm{~s}$ & 23,4 \\
\hline 10 & 4,$18 ; 4,21,2 t, J=6,4 \mathrm{~Hz}$ & 67,6 \\
\hline 11 & $1,96, m$ & 27,9 \\
\hline 12 & $2,43, t, J=7,0 \mathrm{~Hz}$ & 56,5 \\
\hline 13 e 14 & $2,21, s l$ & 45,6 \\
\hline
\end{tabular}

$s=$ singleto; $s l=$ singleto largo; $d=$ dubleto; $t=$ tripleto; $m=$ multipleto; $J=$ constante de acoplamento

Tabela 3. Deslocamentos químicos de $\mathrm{RMN}$ de ${ }^{1} \mathrm{H}(300 \mathrm{MHz})$ e ${ }^{13} \mathrm{C}$ (75 MHz) para o composto (15) em $\mathrm{CDCl}_{3}$

\begin{tabular}{lcc}
\hline posição & $\delta_{\mathrm{H}}$ & $\delta_{\mathrm{C}}$ \\
\hline 1 & $13,33, s$ & 163,8 \\
2 & $6,31, d, \mathrm{~J}=2,1 \mathrm{~Hz}$ & 97,4 \\
3 & & 164,7 \\
4 & $6,37, d, J=2,1 \mathrm{~Hz}$ & 92,7 \\
5 & $6,72, d, J=2,1 \mathrm{~Hz}$ & 99,3 \\
6 & & 162,7 \\
7 & $6,70, d l$ & 115,8 \\
8 & & 143,7 \\
9 & & 182,4 \\
$4 \mathrm{a}$ & & 157,0 \\
$8 \mathrm{a}$ & & 113,6 \\
$9 \mathrm{a}$ & & 104,4 \\
$10 \mathrm{a}$ & & 159,4 \\
$8-\mathrm{CH}_{3}$ & $2,84, s$ & 23,4 \\
10 & $4,19, m$ & 67,6 \\
11 & $3,15, t$ & 60,8 \\
12 & - & 58,3 \\
13 & 1,$37 ; 1,39, s l$ & 24,6 \\
14 & & 19,0 \\
\hline
\end{tabular}

$s=$ singleto; $s l=$ singleto largo; $d=$ dubleto; $d l=$ dubleto largo; $t=$ tripleto; $m=$ multipleto; $J=$ constante de acoplamento
${ }^{\circ} \mathrm{C}$, com atmosfera contendo $5 \%$ de $\mathrm{CO}_{2}$.

As células foram plaqueadas na concentração de $0,1 \times 10^{6}$ cél/ $\mathrm{mL}$ para as linhagens MDA/MB-435 (mama-humano) e SF-295 (glioblastoma-humano), e na concentração de $0,7 \times 10^{5}$ cél $/ \mathrm{mL}$ para a linhagem HCT-8 (cólon-humano). Os compostos foram adicionados em concentração única de $25 \mu \mathrm{g} / \mathrm{mL}$, sendo as placas encubadas por $72 \mathrm{~h}$ em estufa a $37^{\circ} \mathrm{C}$ e atmosfera contendo $5 \%$ de $\mathrm{CO}_{2}$. Ao término deste tempo, as mesmas foram centrifugadas e o sobrenadante removido. Em seguida, adicionou-se $150 \mu \mathrm{L}$ da solução de MTT (brometo de 3-(4,5dimetiltiazol-2-il)-2,5-difeniltetrazólio) e as placas foram incubadas por $3 \mathrm{~h}$. A absorbância foi lida após dissolução do precipitado com $150 \mu \mathrm{L}$ de DMSO em espectrofotômetro de placa a $590 \mathrm{~nm}$.

Os experimentos foram analisados segundo a média \pm desvio padrão da média (DPM) da inibição do crescimento celular usando o programa GraphPad Prism. Cada amostra foi analisada a partir de dois experimentos realizados em triplicata.

\section{Atividade antibiótica}

Um inóculo bacteriano foi preparado com 3-5 colônias em caldo Müller-Hinton e em seguida incubado por $5 \mathrm{~h}$ a $37^{\circ} \mathrm{C}$. Após esse período, foi diluído em solução salina $0,45 \%$ e semeado, com auxílio de $s w a b$ estéril em placas de Petri contendo agar Müller-Hinton com sangue de carneiro a 5\% (S. aureus -ATCC 25923) e sem sangue ( $E$. coli - ATCC 25922).

As amostras foram solubilizadas em DMSO a uma concentração média de $10 \mathrm{mg} / \mathrm{mL}$ e aplicadas sobre papel de filtro autoclavados (espessura de $0,38 \mathrm{~mm}$ e diâmetro de $6 \mathrm{~mm}$ ) com pipeta automática de 20 $\mu \mathrm{L}$, sendo aplicadas $200 \mu \mathrm{g}$ de cada substância. Na mesma placa foram colocados discos com DMSO e o antibiótico amicacina, usado como padrão positivo. Após $24 \mathrm{~h}$ de incubação a $37^{\circ} \mathrm{C}$, a atividade antibiótica foi avaliada através da medida do halo de inibição (mm).

\section{RESULTADOS E DISCUSSÃO}

Os liquens são notadamente importantes fontes de compostos de natureza fenólica. Do líquen Parmotrema lichexanthonicum foram isolados a depsidona ácido salazínico (1), a xantona liquexantona (2) e o depsídeo atranorina (3), como constituintes majoritários. As substâncias (1) e (2) foram isoladas com bons rendimentos, o que, associado ao grande interesse biológico mostrado por substâncias destas classes, tornou estas duas substâncias interessantes para a obtenção de derivados.

\section{Derivados do ácido salazínico}

O ácido salazínico (1) foi tratado com os álcoois $n$-propanol, $n$ butanol, $n$-pentanol, $n$-hexanol, iso-propanol e terc-butanol, a uma temperatura de $90{ }^{\circ} \mathrm{C}$, exceto para os dois álcoois ramificados que foram aquecidos até temperatura de refluxo. ${ }^{44}$

Os espectros de $\mathrm{RMN}$ de ${ }^{1} \mathrm{H}$, dos produtos (4) a (6), (8) e (9) mostram a presença dos mesmos sinais do esqueleto da depsidona e ainda sinais referentes a hidrogênios de cadeias alquílicas (de 0,8 a 3,5 ppm), onde as integrações das áreas dos picos indicam a presença de duas dessas cadeias. Além disso, a ausência do sinal largo da hidroxila do anel lactol, na região de 8 ppm, sugeriu a inserção de um dos grupos na posição 8 '.

Os espectros de $\mathrm{RMN}$ de ${ }^{13} \mathrm{C}$ dos compostos apresentam todos os sinais das cadeias alquílicas duplicados, com 2 sinais de grupos metileno na faixa de 70 ppm, que são referentes aos grupos metilênicos oxigenados. Os espectros apresentam ainda os mesmos sinais do espectro do ácido salazínico, com leves alterações de cerca de 1 a 2 ppm, com exceção de dois sinais: um em aproximadamente 100 ppm (metino) e outro em aproximadamente 60 ppm (metileno). Estes sinais podem ser atribuídos, respectivamente, aos carbonos 8' e 9' dos 
derivados, que têm valores de deslocamento químico de 94,9 e 52,7 ppm, no espectro do ácido salazínico (1). As correlações obtidas pelo espectro de $\mathrm{HMBC}$ do derivado proveniente da reação do ácido salazínico com $n$-hexanol confirmam a atribuição, com uma correlação entre o sinal em 6,45 ppm (H-8') e o sinal em 70,1 ppm, e do sinal em 4,70 ppm (H-9') e o sinal em 71,9 ppm. Com base nestas informações, foi possível determinar que a inserção das cadeias alquílicas na molécula do ácido salazínico se dá nas posições 8' e 9', produzindo os derivados (4) a (6), (8) e (9), produtos de substituição das duas hidroxilas benzílicas. A reação do ácido salazínico com terc-butanol produziu o ácido 9'-O-terc-butil salazínico (7). O espectro de RMN de ${ }^{1} \mathrm{H}$ de (7) mostra que houve a inserção de uma cadeia alquílica apenas, o que é confirmado pelo espectro de RMN de ${ }^{13} \mathrm{C}$. O espectro de HMBC do derivado mostra uma correlação entre o sinal do H-9' e o sinal em 76,2 ppm, do carbono quaternário do grupo terc-butila. Este produto já havia sido relatado por Huneck e Tabacchi. ${ }^{44}$ Provavelmente, a posição 9' é mais favorecida para substituição por este grupo volumoso por ser menos impedida estericamente que a posição 8'.

Devido, principalmente, à característica estrutural do substrato e às condições da reação, sugere-se que estas reações de substituição devem seguir um mecanismo do tipo nucleofílica unimolecular $\left(\mathrm{S}_{\mathrm{N}} 1\right)$, com a formação de carbocátions benzílicos estáveis nas posições 8 , e 9', através da saída das hidroxilas protonadas. Isto deve ser possível por meio de auto catálise ácida, já que algumas das hidroxilas fenólicas do ácido salazínico têm acidez relativamente elevada, com valores de pKa de 5,39 e 8,71.

\section{Derivados da liquexantona}

\section{Reações de desmetilação da liquexantona}

As reações de desmetilação da liquexantona (2) foram realizadas com o objetivo de produzir o derivado totalmente desmetilado, a norliquexantona (10), e os derivados mono-metilados, a 3-O-metil (11) e a 6-O-metilnorliquexantona (11').

A fim de obter (10) foi realizada uma reação de desmetilação com $\mathrm{BBr}_{3}{ }^{45} \mathrm{O}$ espectro de $\mathrm{RMN}$ de ${ }^{1} \mathrm{H}$ do produto apresentou sinais para uma metila aromática em 2,71 ppm, um sinal para uma hidroxila fenólica em 13,40 ppm e 4 hidrogênios aromáticos, como é observado no espectro da liquexantona (2). Entretanto, a ausência dos sinais das metoxilas, na região de aproximadamente $3,5 \mathrm{ppm}$, confirmou a obtenção do produto esperado, a norliquexantona (10) (Figura 3).

$\mathrm{O}$ espectro de RMN de ${ }^{13} \mathrm{C}$ do produto confirma a estrutura da norliquexantona (10), apresentando basicamente os mesmos sinais do espectro de ${ }^{13} \mathrm{C}$ da liquexantona (2), com exceção dos sinais das metoxilas, na região de 55 ppm, que não aparecem, e uma pequena desproteção dos sinais dos hidrogênios metínicos aromáticos.

Para a obtenção dos produtos de desmetilação parcial da liquexantona<smiles>Cc1cc(O)cc2oc3cc(O)cc(O)c3c(=O)c12</smiles>

(10)<smiles>COc1cc(O)c2c(=O)c3c(C)cc(O)cc3oc2c1</smiles>

(11)<smiles>COc1cc(C)c2c(=O)c3c(O)cc(O)cc3oc2c1</smiles>

$\left(11^{\prime}\right)$

Figura 3. Produtos (10) e (11) produzidos a partir de reações de desmetilação da liquexantona (2), e (11'), não obtido
(2), foram realizadas três tentativas sem sucesso: utilizando cloridrato de piridina, auxiliada por microondas, segundo o procedimento descrito por Kulkarni e colaboradores; ${ }^{46}$ utilizando $\mathrm{HBr}$ dissolvido em ácido acético, segundo a metodologia descrita por Joshi e colaboradores ${ }^{47}$ e, a reação com $\mathrm{BCl}_{3} \cdot{ }^{45} \mathrm{Em}$ todos os casos os produtos esperados não foram obtidos e houve apenas a recuperação do material de partida.

Outra alternativa para a obtenção dos derivados monometilados foi a reação com $\mathrm{KOH}$ em dietilenoglicol (DEG), a uma temperatura de aproximadamente $240{ }^{\circ} \mathrm{C} .{ }^{48} \mathrm{Nesta}$ reação foi obtida a norliquexantona (10) e um produto menos polar. O espectro de RMN de ${ }^{1} \mathrm{H}$ deste produto mostrou-se muito semelhante ao da norliquexantona (10), mas apresentou um sinal para uma metoxila, na região de 3,9 ppm, indicando tratar-se de um dos derivados monometilados. Pelo espectro de RMN de ${ }^{13} \mathrm{C}$ do produto foi possível localizar a metoxila na posição 3 do esqueleto xantônico devido, principalmente, a uma pequena proteção nos sinais dos carbonos 2 e 4 do produto com relação aos da norliquexantona, que resultam de um efeito $\gamma$ de proteção da metila ligada ao oxigênio da posição 3. Isso foi confirmado pelo espectro de $g \mathrm{HMBC}$, que mostra uma correlação entre o sinal em 3,9 com o sinal em 165,7 ppm, referente ao carbono 3. Assim, o produto obtido foi a 3-O-metilnorliquexantona (11) (Figura 3).

\section{Obtenção da 3-O-metil-6-O-prenilnorliquexantona (12)}

O composto (11) foi prenilado com brometo de 3,3-dimetilalila, obtendo-se a 3-O-metil-6- $O$-prenilnorliquexantona (12) (Figura 4). Picos em 5,49 ppm (tripleto) e em 4,58 ppm (dubleto) no espectro de RMN de ${ }^{1} \mathrm{H}$ confirmaram a $O$-prenilação.

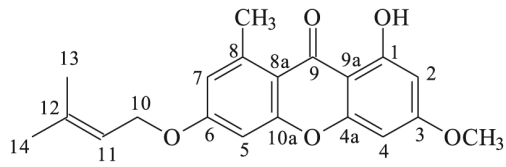

(12)

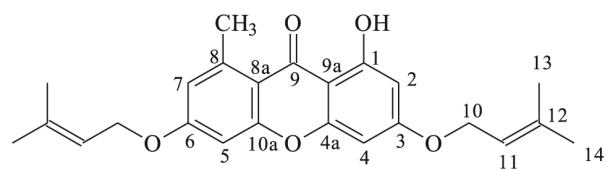

(13)

Figura 4. Produtos (12) e (13) obtidos por prenilação da 3-O-metilnorliquexantona $(\mathbf{1 1})$ e da norliquexantona $(\mathbf{1 0})$, respectivamente

\section{Reações de prenilação}

A fim de obter derivados prenilados da liquexantona (2), várias condições de reação foram testadas utilizando o brometo de 3,3dimetilalila e o 2-metil-3-buten-2-ol.

$\mathrm{Na}$ reação com brometo de 3,3-dimetilalila em meio básico ${ }^{49}$ pôde-se observar, pelo espectro $\mathrm{RMN}$ de ${ }^{1} \mathrm{H}$ da mistura reacional, que houve reação de prenilação, pelo aparecimento de sinais na região de 3,3 e 5,2 ppm, atribuídos aos produtos $C$-prenilados, e sinais na região de 4,7 e 5,5 ppm, atribuíveis aos produtos $O$-prenilados, entretanto em baixa proporção. $\mathrm{O}$ mesmo foi observado para a reação utilizando 2-metil-3-buten-2-ol, ${ }^{50}$ mas neste caso, apenas derivados C-prenilados foram produzidos.

\section{Reações de prenilação da norliquexantona $(\mathbf{1 0})$}

O composto (10) foi prenilado com brometo de 3,3-dimetilalila, ${ }^{49}$ sendo recuperada uma parte do material de partida e isolado um produto majoritário. 
O espectro de $\mathrm{RMN}$ de ${ }^{1} \mathrm{H}$ deste produto apresentou sinais atribuíveis a dois grupos $O$-prenila, com sinais de metilas em aproximadamente 1,7 e 1,8 ppm, dois dubletos na região de 4,5 ppm compatíveis com dois grupos metileno ligados ao oxigênio, e um sinal largo, na região de 5,5 ppm, atribuído aos hidrogênios olefínicos dos substituintes. O espectro de $\mathrm{RMN}$ de ${ }^{13} \mathrm{C}$ também confirmou a presença de duas unidades, pois os sinais característicos para o grupo, em 18, 25, 65, 118 e 139 ppm, se apresentaram dobrados. Pela análise dos dados espectrais (Tabela 1) foi possível concluir que o composto produzido foi o derivado di- $O$-prenilado da norliquexantona, 3,6-di-O-prenilnorliquexantona (13) (Figura 4), obtido com um rendimento de aproximadamente $55 \%$.

Obtenção da 3,6-bis[3-(dimetilamino)propóxi]-1-hidróxi-8-metil9H-xanten-9-ona $(\mathbf{1 4})^{51}$

Como os oxigênios ligados aos carbonos 3 e 6 da norliquexantona (10) podem atuar como nucleófilos, foi realizada uma reação de substituição com hidrocloreto de (3-cloropropil)dimetilamônio, a fim de obter a 3,6-bis[3-(dimetilamino)propóxi]-1-hidróxi-8-metil9H-xanten-9-ona (14).

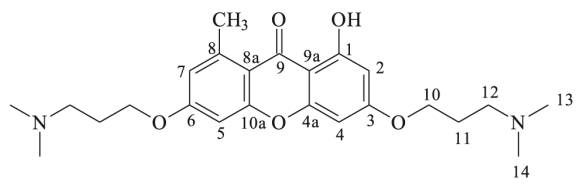

(14)

Figura 5. Estrutura química da 3,6-bis[3-(dimetilamino)propóxi]-1-hidróxi8-metil-9H-xanten-9-ona (14)

O espectro de $\mathrm{RMN}$ de ${ }^{1} \mathrm{H}$ de (14) mostra dois tripletes na região de 4,2 ppm, que podem ser atribuídos a dois grupos metileno ligados a oxigênio, além de sinais entre 1,9 e 2,5 ppm referentes aos demais hidrogênios dos substituintes. No espectro de RMN de ${ }^{13} \mathrm{C}$, além dos sinais do esqueleto da xantona, foi possível observar sinais de 3 grupos metileno, um em 67,6 ppm, compatível com um - $\mathrm{CH}_{2}$ - ligado a oxigênio, outro em 56,5 ppm, atribuível a metileno ligado a nitrogênio, e um em 27,9 ppm, referente ao grupo localizado entre os outros dois carbonos. Também foi observado um sinal de grupo metila, bastante intenso, em 45,6 ppm, característico de metila ligada a nitrogênio. Estas informações, associadas àquelas obtidas pelo espectro de RMN de ${ }^{1} \mathrm{H}$ (Tabela 1), permitiram confirmar o produto da reação como sendo a 3,6-bis[3-(dimetilamino)propóxi]-1-hidróxi-8-metil-9Hxanten-9-ona (14) (Figura 4), obtida com 62,5\% de rendimento.

Obtenção da 3,6-bis[(3,3-dimetiloxiran-2-il)metóxi]-1-hidróxi-8metil-9H-xanten-9-ona $(\mathbf{1 5})^{52}$

Outra reação realizada com o derivado di-prenilado foi a epoxidação das ligações duplas dos dois grupos prenila, pelo tratamento do composto (13) com ácido metacloroperbenzóico (MCPBA).

No espectro de $\mathrm{RMN}$ de ${ }^{1} \mathrm{H}$ do produto majoritário da reação observou-se, além dos sinais característicos para o esqueleto da xantona, um tripleto, em 3,2 ppm, dois grupos de sinais na região entre 4,0 e 4,3 ppm, e quatro sinais em aproximadamente 1,4 ppm. Estes sinais são compatíveis com a inserção de um oxigênio, sob a forma de um anel epóxido, na dupla ligação de um grupo prenila de (13). O desaparecimento do sinal dos hidrogênios olefínicos dos grupos prenila, em 5 ppm confirmou que a reação aconteceu nos dois pontos possíveis, e o produto é a substância di-epoxidada.

No espectro de $\mathrm{RMN}$ de ${ }^{13} \mathrm{C}$ foram observados sinais em 67,7 ppm, atribuíveis a um grupo metileno ligado a oxigênio, em 60,8 ppm (metino) e em 58,3 ppm, referente a um carbono tetrassubstituído, ambos no anel epóxido. Os sinais das metilas ligadas ao anel oxirano foram observados em 19,0 e 24,6 ppm. Todos estes dados reunidos (Tabela 3) confirmaram que um dos produtos obtidos na reação foi a 3,6-bis[(3,3-dimetiloxiran2-il)metóxi]-1-hidróxi-8-metil-9H-xanten-9-ona (15) (Figura 6).

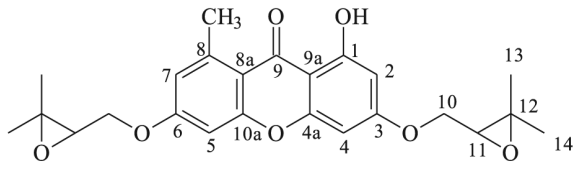

(15)

Figura 6. Estrutura química da 3,6-bis[(3,3-dimetiloxiran-2-il)metóxi]-1hidróxi-8-metil-9H-xanten-9-ona (15)

\section{Atividade citotóxica}

As atividades citotóxicas do ácido salazínico (1) e seus derivados com cadeias alquílicas lineares $(\mathbf{4}),(\mathbf{6}),(\mathbf{8})$ e (9), juntamente com as da liquexantona (2) e compostos (10), (11) e (13) estão apresentadas na Tabela 4, com seus respectivos percentuais de inibição.

Apenas as substâncias que apresentaram atividade de inibição do crescimento das células tumorais maiores que $90 \%$ no ensaio preliminar com dose única de $25 \mu \mathrm{g} / \mathrm{mL}$ foram selecionadas para a determinação do valor da $\mathrm{CI}_{50}$. Os valores estão apresentados na Tabela 5.

Tabela 4. Percentual de inibição do crescimento celular obtido com as amostras nas diferentes linhagens tumorais em dose única de 25 $\mu \mathrm{g} / \mathrm{mL}$

\begin{tabular}{lccc}
\hline Substâncias & $\begin{array}{c}\text { MDA-MB435 } \\
\text { média }\end{array}$ & $\begin{array}{c}\text { HCT-8 } \\
\text { média }\end{array}$ & $\begin{array}{c}\text { SF-295 } \\
\text { média }\end{array}$ \\
\hline Ácido salazínico (1) & 14,69 & $-1,63$ & 13,01 \\
$\begin{array}{l}\text { Liquexantona (2) } \\
\text { Ácido 8', 9' -di- } O \text { - } n \text {-propil } \\
\text { salazínico (4) }\end{array}$ & 30,72 & 38,95 & 26,46 \\
$\begin{array}{l}\text { Ácido 8', 9' -di- } O \text { - } n \text {-butil } \\
\text { salazínico (6) }\end{array}$ & 96,92 & 93,12 & 72,02 \\
$\begin{array}{l}\text { Ácido 8', 9' -di- } O \text { - } n \text {-pentil } \\
\text { salazínico (8) }\end{array}$ & 54,77 & 102,91 & 100,09 \\
$\begin{array}{l}\text { Ácido 8', 9' -di- } O \text { - } n \text {-hexil } \\
\text { salazínico (9) }\end{array}$ & 7,66 & 99,65 & 101,22 \\
$\begin{array}{l}\text { Norliquexantona (10) } \\
\text { 3- } O \text {-metilnorliquexantona (11) }\end{array}$ & 67,46 & 81,87 & 54,63 \\
$\begin{array}{l}\text { 3,6-di- } O \text {-prenilnorliquexantona } \\
\text { (13) }\end{array}$ & 41,84 & 34,96 & 40,24 \\
\hline
\end{tabular}

Tabela 5. Atividade citotóxica $-\mathrm{CI}_{50}(\mu \mathrm{g} / \mathrm{mL})-$ dos derivados $(6)$, (8) e (9)

\begin{tabular}{lccc}
\hline Substâncias & \multicolumn{3}{c}{$\mathrm{CI}_{50}(\mu \mathrm{g} / \mathrm{mL})$} \\
& MDA/ MB-435 & HCT-8 & SF-295 \\
\hline $\begin{array}{l}\text { Ácido 8', 9'- } \\
\text { di- } O \text { - } n \text {-butil }\end{array}$ & 18,32 & 8,00 & 17,12 \\
salazínico (6) & $12,28-27,34^{*}$ & $5,07-12,62$ & $10,27-28,55$ \\
$\begin{array}{l}\text { Ácido 8', 9'- } \\
\text { di- } O \text { - } n \text {-pentil }\end{array}$ & 21,66 & 4,28 & 11,93 \\
salazínico (8) & $21,66-53,49$ & $3,07-5,98$ & $7,93-17,94$ \\
$\begin{array}{l}\text { Ácido 8', 9'- } \\
\text { di- } O \text { - } n \text {-hexil }\end{array}$ & 7,45 & 1,73 & 5,69 \\
salazínico (9) & $4,83-11,50$ & $1,30-2,31$ & $3,14-10,30$ \\
\hline
\end{tabular}

*Intervalo de confiança. 
Os resultados indicam que a liquexantona (2) e seus derivados (10), (11) e (13) não apresentam potencial citotóxico.

Para os derivados do ácido salazínico (4), (6), (8) e (9) os resultados do ensaio mostram que o alongamento da cadeia alquílica causa um aumento na atividade citotóxica destes derivados, sendo os ácidos 8', 9'-di-O-n-pentil salazínico (8) e 8', 9'-di-O-n-hexil salazínico (9) potencialmente ativos para as células HCT-8.

\section{Atividade antibiótica}

Os resultados da avaliação da atividade antibiótica do ácido salazínico (1) e seus derivados (4) a (9), juntamente com a liquexantona (2) e os derivados (10), (11), (13) e (14), frente às bactérias Escherichia coli e Staphylococcus aureus, constam na Tabela 6.

Tabela 6. Resultados da atividade antibiótica das substâncias (1) a (11), (13) e (14) frente a $E$. coli e $S$. aureus utilizando o ensaio de disco

\begin{tabular}{lcc}
\hline Substâncias & $\begin{array}{c}\text { E. coli } \\
(\mathrm{mm})\end{array}$ & $\begin{array}{c}\text { S. aureus } \\
(\mathrm{mm})\end{array}$ \\
\hline Ácido salazínico (1) & 8 & n.a \\
Liquexantona (2) & 8 & n.a \\
Ácido 8', 9'-di- $O$ - $n$-propil salazínico (4) & 9 & 10 \\
Ácido 8', 9'-di- $O$-isopropil salazínico (5) & 9 & 10 \\
Ácido 8', 9'-di- $O$ - $n$-butil salazínico (6) & 10 & 11 \\
Ácido 9' -O-terc-butil salazínico (7) & 10 & 10 \\
Ácido 8', 9'-di-O- $n$-pentil salazínico (8) & 10 & 10 \\
Ácido 8', 9'-di- $O$ - $n$-hexil salazínico (9) & 8 & 10 \\
Norliquexantona (10) & 10 & n.a \\
3-O-metilnorliquexantona (11) & 12 & 11 \\
3,6-di- $O$-prenilnorliquexantona (13) & 10 & n.a \\
3,6-bis[3-(dimetilamino)propóxi]-1- & 12 & 20 \\
hidróxi-8-metil-9H-xanten-9-ona (14) & 30 & 30 \\
Amicacina &
\end{tabular}

$\mathrm{mm}=$ diâmetro do halo de inibição do crescimento bacteriano em $\mathrm{mm} ;($ n.a) $=$ não ativo

Pôde-se observar que a atividade do ácido salazínico (1) e de seus derivados (4) a (9) foi baixa frente às duas bactérias, em comparação a atividade do antibiótico padrão, amicacina. O ácido salazínico (1) apresentou atividade apenas sobre $E$. coli, enquanto que os seus derivados foram ativos frente às duas bactérias. No caso da liquexantona (2) e seus derivados (10), (11), (13) e (14), apenas a xantona com cadeia alquílica nitrogenada (14) mostrou-se a mais ativa entre as substâncias avaliadas, especialmente frente à $S$. aureus, com um halo de inibição de $20 \mathrm{~mm}$. Os demais compostos apresentaram baixa atividade frente às duas bactérias, sendo que os compostos $(\mathbf{1 0})$ e (13) não foram ativos sobre $S$. aureus.

\section{CONCLUSÃO}

O líquen Parmotrema lichexanthonicum mostrou-se uma fonte potencial da depsidona ácido salazínico (1) e da xantona liquexantona (2), dos quais foram preparados outros produtos por modificações estruturais. A série homologa dos ácidos 8',9'-di- $O$-alquil salazínicos (4) - (9) mostrou resultados promissores na avaliação da atividade citotóxica, sendo os derivados (6), (8) e (9) os mais ativos, com valores de $\mathrm{CI}_{50}$ de até $1,73 \mu \mathrm{g} / \mathrm{mL}$. Já com relação à atividade antibiótica, o ácido salazínico (1) e todos os derivados foram pouco ativos. A liquexantona (2) e seus derivados (10), (11), (13) e (14) foram pouco ativos frente às linhagens de células testadas no ensaio para atividade citotóxica, bem como frente às bactérias $E$. coli e $S$. aureus, com exceção apenas de 3,6-bis[3-(dimetilamino)propóxi]-1-hidróxi-8metil-9H-xanten-9-ona (14), mais ativa frente à $S$. aureus .

\section{AGRADECIMENTOS}

Ao Dr. M. P. Marcelli e ao doutorando A. Spielmann (IBT - São Paulo) pela identificação do líquen. À Fundação de Apoio ao Desenvolvimento de Ensino, Ciência e Tecnologia de Mato Grosso do Sul (FUNDECT/MS) pela bolsa concedida e pelo apoio financeiro. Ao Prof. Dr. C. F. Tormena (UNICAMP), pela obtenção dos espectros de massas de alta resolução.

\section{REFERÊNCIAS}

1. Nash III, T. H.; Lichen Biology, Cambridge University Press: Great Britain, 1996.

2. Wang, C.; Maier, U. H.; Keil, M.; Zenk, M. H.; Bacher, A.; Rohdich, F.; Eisenreich, W.; Eur. J. Biochem. 2003, 270, 2950.

3. Xu, Y.; Chiang, P.; Lai, Y.; Vittal, J. J.; Wu, X.; Tan, B. K. H.; Imiyabir, Z.; Goh, S.; J. Nat. Prod. 2000, 63, 1361.

4. Hill, J. G.; Nakashima, T. T.; Vederas, J. C.; J. Am. Chem. Soc. 1982, 104,1745

5. Lawrey, J. D.; Organisms, Processes and Applications, American Chemical Society: Washington, DC, 1995.

6. Ingólfsdóttir, K.; Chung, G. A. C.; Skúlason, V. G.; Gissurarson, S. R.; Vilhelmstóttir, M.; Eur. J. Pharm. Sci. 1998, 6, 141.

7. Cohen, P. A.; Hudson, J. B.; Towers, G. H. N.; Experientia 1996, 52 , 180.

8. Neamati, N.; Hong, H.; Mazumder, A.; Wang, S.; Sunder, S.; Nicklaus, M. C.; Milne, G. W. A.; Proska, B.; Pommier, Y.; J. Med. Chem. 1997, 40,942 .

9. Umezawa, K.; Muramatsu, S.; Ishizuka, M.; Sawa, T.; Takeushi, T.; Matsushima, T.; Biochem. Biophys. Res. Commun. 1983, 110, 733.

10. Matsubara, H.; Kinoshita, K.; Koyama, K.; Takahashi, K.; Yoshimura, Y.; Yamamoto, Y.; Miura, Y.; Kinoshita, Y.; J. Hattori Bot. Lab. 1997, $83,179$.

11. Ogmundsdóttir, H. M.; Zoëga, G. M.; Gissurarson, S. R.; Ingólfsdóttir, K.; J. Pharm. Pharmacol. 1998, 50, 107.

12. Ingólfsdóttir, K.; Gudmundsdóttir, G. F.; Ogmundsdóttir, H. M.; Paulus, K.; Haraldsdóttir, S.; Kristisson, H.; Bauer, R.; Phytomedicine 2002, 9 , 654.

13. Kumar, S. K. C.; Müller, K.; Eur. J. Med. Chem. 1999, 34, 1035.

14. Kumar, S. K. C.; Müller, K.; J. Nat. Prod. 1999, 62, 817.

15. Kumar, S. K. C.; Müller, K.; Eur. J. Med. Chem. 2000, 35, 405.

16. Pereira, E. C.; Nascimento, S. C.; Lima, R. C.; Silva, N. H.; Oliveira, A. F. M.; Bandeira, E.; Boitard, M.; Beriel, H.; Vicente, C.; Legaz, M. E.; Tokai J. Exp. Clin. Med. 1994, 19, 47.

17. Lima, R. M. O. C.; Nascimento, S. C.; Pereira, E. C.; Honda, N. K.; Devincenzi, I. A. A.; Alves, R. C.; XIV Simpósio de Plantas Medicinais do Brasil, Florianópolis, Brasil, 1996.

18. Ernst-Russell, M. A.; Chai, C. L. L.; Hurne, A. M.; Waring, P.; Hockless, D. C. R.; Eliz, J. A.; Aust. J. Chem. 1999, 52, 279.

19. Shibata, S.; Miura, Y.; Jap. Med. J. 1948, 1, 152.

20. Cain, B. F.; J. Chem. Soc. 1966, 1041.

21. Takai, M.; Uehara, Y.; Beisler, J. A.; J. Med. Chem. 1979, 22, 1380.

22. Saraiva, L.; Fresco, P.; Pinto, E.; Saouza, E.; Pinto, M.; Gonçalves, J.; Bioorg. Med Chem. 2003, 11, 1215.

23. Kwok, Y.; Zeng, Q.; Hurley, L. H.; Proc. Natl. Acad. Sci. U.S.A. 1998, 95,13531 
24. Woo, S.; Jung, J.; Lee, C.; Kwon, Y.; Na, Y.; Bioorg. Med. Chem. 2007, $17,1163$.

25. Piazzi, L.; Belluti, F.; Bisi, A.; Gobbi, S.; Rizzo, S.; Bartolini, M.; Andrisano, V.; Recanatini, M.; Rampa, A.; Bioorg. Med. Chem. 2007, 15, 575 .

26. Nakatani, K.; Nakahata, N.; Arakawa, T.; Yasuda, H.; Ohizumi, Y.; Biochem. Pharmacol. 2002, 63, 73.

27. Zou, J.; Jin, D.; Chen, W.; Wang, J.; Liu, Q.; Zhu, X.; Zhao, W.; J. Nat. Prod. 2005, 68, 1514.

28. Núñez, M. B.; Maguna, F. P.; Okulik, N. B.; Castro, A. E.; Bioorg. Med. Chem. 2004, 14, 5611.

29. Ng, T. B.; Huang, B.; Fong, W. P.; Yeung, H. W.; Life Sci. 1997, 10, 933.

30. Groweiss, A.; Cardellina, I. J. H.; Boyd, M. R.; J. Nat. Prod. 2000, 60, 1537.

31. Portela, C.; Afonso, C. M. M.; Pinto, M. M. M.; Ramos, M. J.; J. Comput.-Aided Mol. Des. 2003, 17, 583

32. Riscoe, M.; Kelly, J. X.; Winter, R.; Cur. Med. Chem. 2005, 12, 2539.

33. Wang, L.; Kang, J.; Chen, I.; Teng, C.; Lin, C.; Bioorg. Med. Chem. 2002, 10, 567 .

34. Matsumoto, K.; Akao, Y.; Kobayashi, E.; Ohguchi, K.; Ito, T.; Tanaka, T.; Iinuma, M.; Nozawa, Y.; J. Nat. Prod. 2003, 66, 1124.

35. Gobbi, S.; Rampa, A.; Bisi, A.; Belluti, F.; Valenti, P.; Caputo, A.; Zampiron, A.; Carrara, M.; J. Med. Chem. 2002, 45, 4931.

36. Pinto, M. M. M.; Sousa, M. E.; Nascimento, M. S. J.; Curr. Med. Chem. 2005, 12, 2517.

37. Hamano, K.; Kinoshitaokami, M.; Hemmi, A.; Sato, A.; Hisamoto, M.; Matsuda, K.; Yoda, K.; Haruyama, H.; Hosoya, T.; Tanzawa, K.; J. Antibiot. 1992, 45, 1195.
38. Permana, D.; Lajis, N. H.; Mackeen, M. M.; Ali, A. M.; Kitajima, M.; Takayama, H.; J. Nat. Prod. 2001, 64, 976.

39. Permana, D.; Abas, F.; Maulidiani; Shaari, K.; Stanslas, J.; Ali, A. M.; Lajis, N. H.; Z. Naturforsch., C: J. Biosci. 2005, 60, 523.

40. Correche, E. R.; Enriz, R. D.; Piovano, M.; Garbarino, J.; GomezLechon, M. J.; ATLA, Altern. Lab. Anim. 2004, 32, 605.

41. Ito, C.; Itoigawa, M.; Mishina, Y.; Tomiyasu, H.; Litaudon, M.; Cosson, J.; Mukainaka, T.; Tokuda, H.; Nishino, H.; Furukawa, H.; J. Nat. Prod. 2001, 64, 147.

42. Huneck, S.; Yoshimura, I.; Identification of lichen substances, SpringerVerlag: Berlin, Heindelberg, 1996.

43. König, G. M.; Wright, A. D.; Phytochem. Anal. 1999, 10, 279.

44. Huneck, S.; Tabacchi, R.; Phytochemistry 1987, 26, 1131.

45. Elix, J. A.; Gaul, K. L.; Jian, H.; Aust. J. Chem. 1993, 46, 95.

46. Kulkarni, P. P.; Kadam, A. J.; Mane, R. B.; Desai, U. V.; Wadgaonkar, P. P.; J. Chem. Res. 1999, (S), 394.

47. Joshi, B. S.; Srivastava, S. K.; Barber, A. D.; Desai, H. K.; Pelletier, S. W.; J. Nat. Prod. 1997, 60, 439.

48. Cavalheri, P. S.; Oikawa, C. M. M.; Nobre, J. A. V. S.; Severino, E. A.; Muzzi, R. M.; Resumos do XXVI Congresso Latino Americano de Química e 27a Reunião Anual da Sociedade Brasileira de Química, Salvador, Brasil, 2004.

49. Tchamo, D. N.; Dijoux-Franca, M.; Mariotte, A.; Tsamo, E.; Daskiewicz, J. B.; Bayet, C.; Barron, D.; Conseil, G.; Di Pietro, A.; Bioorg. Med. Chem. Lett. 2000, 10, 1343.

50. Jain, A. C.; Lal, P.; Seshadri, T. R.; Tetrahedron 1970, 26, 2631.

51. Hunter, D. H.; Ponce, Y. Z.; Brown, G. W.; Chamberlain, M. J.; Driedger, A. A.; Morrissey, G.; Can. J. Chem. 1984, 62, 2015.

52. Ma, E.; Kim, J.; Molecules 2003, 8, 886. 